OPEN ACCESS

Edited by:

Marco Casazza,

University of Naples Parthenope, Italy

Reviewed by:

Jeffery Sullivan,

Natural Systems Analysts Inc.,

United States

Mohammad Imam Hasan Reza, Presidency Education, Bangladesh

*Correspondence: Haipeng Wu wuhaipeng0701@126.com

Specialty section:

This article was submitted to Environmental Informatics and Remote Sensing,

a section of the journal Frontiers in Environmental Science

Received: 11 October 2021 Accepted: 17 December 2021

Published: 20 January 2022

Citation:

Qu X, Du C, Wu H, Xiong Y, Yu G, Wang J, Dai J, Wu L, Zhang Z, Zhu Y

and Liu J (2022) Effects of Poplar Ecological Retreat on Habitat Suitability for Migratory Birds in China's Dongting

Lake Wetland.

Front. Environ. Sci. 9:793005. doi: 10.3389/fenvs.2021.793005

\section{Effects of Poplar Ecological Retreat on Habitat Suitability for Migratory Birds in China's Dongting Lake Wetland}

\author{
Xinyu $Q u^{1,2}$, Chunyan $D u^{1,2,3}$, Haipeng $W u^{1,2,3 *}$, Ying Xiong ${ }^{1,2,3}$, Guanlong $Y u^{1,2,3}$, \\ Jiasheng Wang ${ }^{4}$, Juan Dai ${ }^{4}$, Lixue Wu ${ }^{1,2}$, Zhuo Zhang ${ }^{1,3}$, Yuqian Zhu ${ }^{1,2}$ and Jingdu Liu ${ }^{1,2}$ \\ ${ }^{1}$ School of Hydraulic Engineering, Changsha University of Science and Technology, Changsha, China, ${ }^{2}$ Engineering and \\ Technical Center of Hunan Provincial Environmental Protection for River-Lake Dredging Pollution Control, Changsha, China, ${ }^{3}$ Key \\ Laboratory of Dongting Lake Aquatic Eco-Environmental Control and Restoration of Hunan Province, Changsha, China, \\ ${ }^{4}$ Changjiang River Scientific Research Institute, Wuhan, China
}

The Poplar Ecological Retreat (PER) project in Dongting Lake wetland is an important measure in response to China's ecological civilization construction policy, it aims to remove eastern cottonwoods (Populus deltoides) that artificial large-scale planted in this area and restore the natural state of the wetland, and has got a lot of attention by society and scholars. However, as one of the most important wintering place for migratory birds in the world, the impact of PER on migratory bird habitats in Dongting Lake wetland has not been evaluated. In this paper, we used the habitat suitability index model based on remote sensing to explore the impact of PER on the four mainly migratory bird guilds (Anatidae, Charadriidae, Ardeidae and Laridae) in Dongting Lake wetland. The suitability included four grades: poorly (0-25), generally (25-50), moderately (50-75), and highly (75-100). The results showed that the area of poplars in Dongting Lake wetland decreased significantly after PER was implemented. There was a negative correlation between poplar area and moderate grade habitat area of Anatidae and Ardeidae, and a positive correlation between poplar area and general grade habitat area. However, there was no significant change in different grades of habitat area of Charadriidae and Laridae after PER. Thus, PER improved the habitat suitability of Anatidae and Ardeidae, but had no significant effect on the suitability of habitat for Charadriidae and Laridae. These conclusions could provide reference for understanding the living conditions of Dongting Lake wetland waterbirds, determining the priority protection areas and maintaining wetland biodiversity.

Keywords: poplar ecological retreat, habitat suitability, migratory bird, Dongting lake, wetland

\section{INTRODUCTION}

Wetland ecosystems are known for their capacity to support biodiversity, it covers only $6.4 \%$ of global area but supports 20\% of known species on Earth (Wu et al., 2019a). There are many rare waterfowls that rely on wetlands for breeding and migration, thus wetlands are also known as bird paradise (Fang et al., 2006). Due to the impact of human activities and climate change, the decline of the quantity and quality of natural wetlands has led to the rapid decrease of wetland waterbirds worldwide (Bai et al., 2018; Ma et al., 2019; Tian et al., 2019). Waterbirds are important members of wetland ecosystems, because they are sensitive to the external environment, they are also considered as good indicators of wetland environmental change (Yuan et al., 2014; Wu et al., 2018; Miranda 
et al., 2019). The study on habitat change of wetland birds is not only of great significance for bird biodiversity protection, but also can provide reference for the health status of wetland ecosystem (Scholtz et al., 2017).

Dongting Lake (DL) is the second largest freshwater lake in China. It is on the list of Ramsar wetlands of international importance and an important stopover and overwintering site of migratory bird migration network in East Asia (Wu et al., 2019b; Wang et al., 2019). Agriculture is well developed in DL district and human productive activities have a great impact on the environment. Because of the reclamation of the lake for farmland and sediment deposition, the area of DL has been reduced by nearly half compared with that of the 1950s (Meng et al., 2017). At the same time, the construction of upstream dams also has a significant impact on the hydrological cycle of DL (Xie et al., 2015; Wu et al., 2017; Wu et al., 2020). Since the introduction of eastern cottonwoods (Populus deltoides) in 1970s, the planting area has increased rapidly due to its strong suitability and good economic benefits (Yanxia et al., 2014). For example, from 1996 to 2013, the poplar planting area in the West DL wetland increased by 9 times, and has become one of the main local landscapes (Jing et al., 2016), which introduces great potential ecological risk to DL wetland (Yanxia et al., 2014).

As an alien species, the poplar has powerful competitiveness and quickly invades the living space of original plants, which may affect the diversity of vegetation under the artificial poplar forest (Li et al., 2014a; Ren et al., 2020). In addition, it is called wetland pumping machine as its intense transpiration, which may aggravate the wetland drought, change the physical and chemical properties of soil, and make the wetland ecosystem succession to the terrestrial ecosystem ( $\mathrm{Li}$ et al., 2014b). Local people describe the poplar forest as "no grass under the trees, no birds on the trees", which reflects that the large-scale planting of poplar has profoundly changed the original ecological balance of wetlands. In October 2017, poplar ecological retreat (PER) project began to be implemented on a large scale, by the end of the year, nearly three million poplar trees were felled within the area of more than 50,000 ha. The same year, all poplar trees in the core areas of nature reserves of DL wetland have been removed. From 2018 to 2020, the government issued a 3-year action plan for the special improvement of the ecological environment of DL, and the PER areas were further expanded to buffer zones and experimental areas. It has been more than 3 years since the PER was implemented in DL, but its impacts on migratory birds has not been evaluated.

Habitat suitability refers to the ability of the environment to provide living conditions for species (Tang et al., 2016). Habitat suitability evaluation is an effective method to evaluate the impact of ecological environment changes on wildlife. Habitat suitability evaluation can use field survey method and modeling method based on habitat variables. Compared with the traditional field survey, the extraction of habitat variables by remote sensing analysis overcomes the shortcomings of the former, which is time-consuming and laborious, and is more suitable for research in a larger range (Hu and Liu, 2014). Therefore, establish a model based on remote sensing gradually occupies a dominant position in the evaluation of habitat suitability.
This study would examine the impacts of PER on the habitat suitability of four migratory bird guilds in DL wetland. It aims to: 1) explore the land cover change of DL wetland after PER;2) analyze the impact of PER on the habitat suitability of different migratory bird in DL; and 3) provide reference for wetland bird protection in DL and other areas.

\section{METHODS}

\section{Study Area}

Dongting Lake (DL) $\left(28^{\circ} 30^{\prime}-29^{\circ} 38^{\prime} \mathrm{N}, 112^{\circ} 18^{\prime}-113^{\circ} 15^{\prime} \mathrm{E}\right)$ is located in the middle reaches of the Yangtze River and in the north of Hunan Province (Li et al., 2013). The existing natural lake area of DL is about 2,625 $\mathrm{km}^{2}$ (Ding and Li, 2011; Hu et al., 2020), which can be divided into three parts: East DL, South DL and West DL. The lake body is connected by numerous river networks and flood channels, and the bottom of the lake inclines slightly from northwest to Southeast (Ding and Li, 2011). DL belongs to the subtropical monsoon climate. The annual average temperature is $16.4-17^{\circ} \mathrm{C}$, the frost-free period is $258-275$ days, and the annual precipitation is $1,100-1,400 \mathrm{~mm}$ (Yang et al., 2009). The rainfall from april to June accounts for more than $50 \%$ of the total annual precipitation. Therefore, the water level of DL begins to rise in april, the flood season is from May to October, and the dry season is from November to april of the next year ( $\mathrm{Li}$ et al., 2011). The huge drop of water level (up to $18 \mathrm{~m}$ ) in wet and dry seasons produces unique natural conditions giving birth to diverse landscapes and rich natural resources, providing habitat for a large number of animals and plants (Guan et al., 2016).

In this study, in order to better explore the impact of PER on the habitat suitability of birds in DL, we integrated the traditional DL regional division method and the recent establishment and adjustment of nature reserve of DL, and divided DL into four regions, including East DL (E-DL), West DL (W-DL), South DL (S-DL) and Hengling Lake (HL). E-DL and W-DL are national nature reserves, S-DL and $\mathrm{HL}$ are provincial nature reserves (Figure 1).

\section{Data Resource and Processing}

Remote sensing is the most important data source in this work. In view of the need to splice two images covering the study area, this study selected 12 scenes (Supplementary Table S1) with the resolution being $30 \mathrm{~m}$ of 6 years from 2014-2019, which were collected from the USGS website (https:/earthexplorer.usgs. gov/). We give priority to landsat8 (OLI) images, but our images also include four Landsat7 (ETM+) images because of the limitation of cloud cover, and the acquisition time span of these images is from the end of November to the beginning of February, but they are still in the winter dry season. All images are L1TP level data thus don't need geometric correction (USGS, 2019).

In this study, eCognition Developer 9.01 (Definiens Imaging $\mathrm{GmbH}$, Munich) based on object-oriented classification was used for land cover interpretation (Tian et al., 2008b). Compared with the traditional pixel-based method, the object-based method not only includes spectral information, but also gives the object shape and grain features, which can significantly reduce the "salt and pepper effect" (Vieira et al., 2012; Ceccarelli et al., 2013; Jia et al., 2013). In 


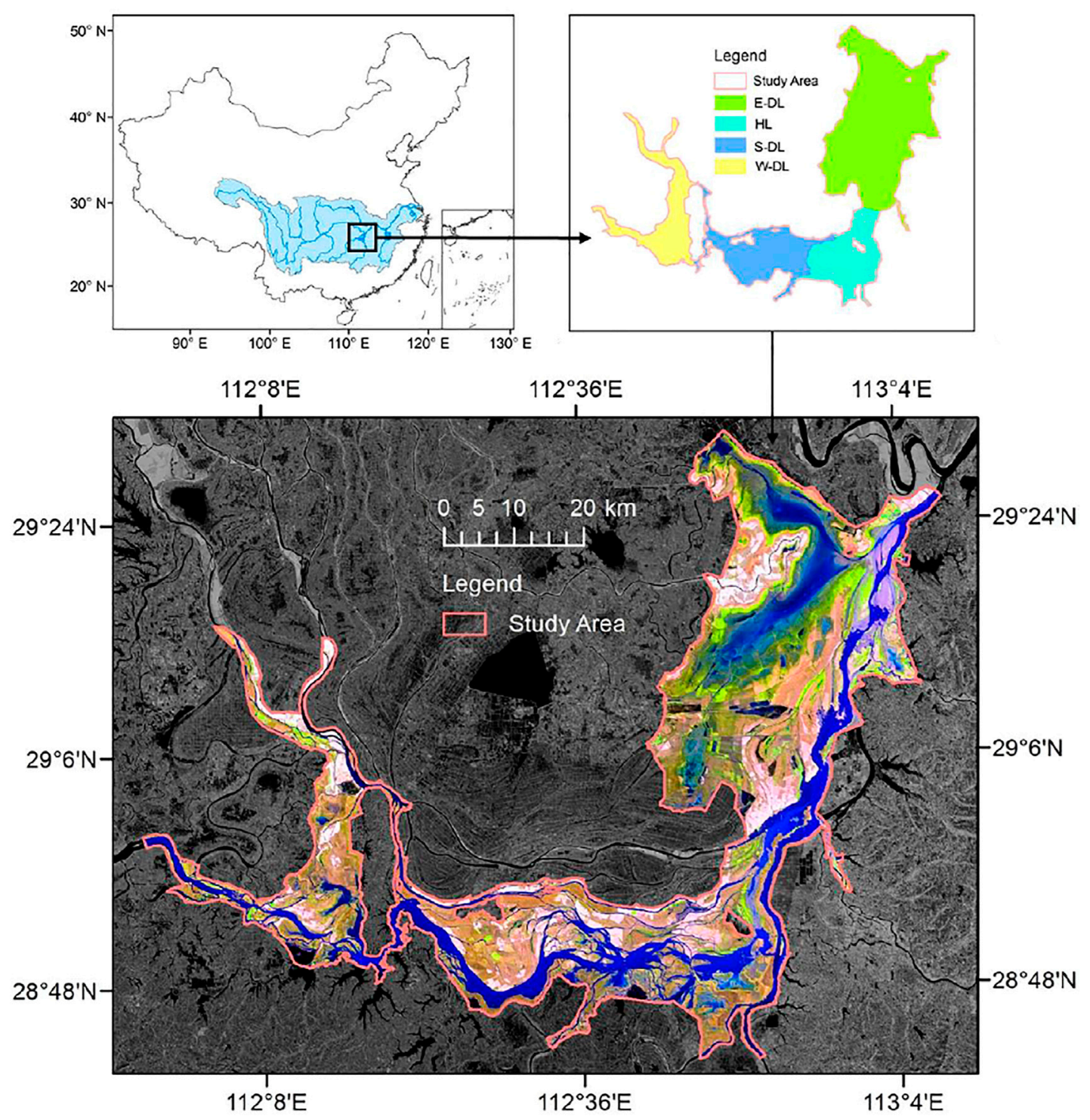

FIGURE 1 | The location of Dongting Lake (DL) and the range of East Dongting Lake (E-DL), Hengling Lake (HL), South Dongting Lake (S-DL) and West Dongting Lake (W-DL).

this study, the multi-scale segmentation provided by eCognition is used for image segmentation, and the ESP2 (Estimation of Scale Parameter 2) plug-in is used to determine the optimal segmentation scale to ensure the accuracy of classification and reduce the workload in the later stage (Drăguț et al., 2010). We select the threshold classification method to classify the land cover of DL, and then we use visual interpretation to correct the misclassified objects. Referring to the previous research, we divided the land cover of DL into six types: forest (poplar accounted for more than 95\%), phragmites, grass, mudflat, shallow water and deep water (Yanxia et al., 2014; Wu et al., 2017). Finally, we use field survey data (30 points, located by GPS) during early December 2019 and Google Earth high-resolution historical images as the true values to establish the confusion matrix (Tian et al., 2019). The results show that the accuracy of classification is $86-90 \%$, and the kappa value is between
0.83-0.86. It can be used for follow-up study (Tang et al., 2016; Hu et al., 2020).

\section{Establish Habitat Suitability Model}

Habitat suitability index (HSI) model is a commonly used model to study the change of habitat suitability of species (Li et al., 2019; Powers and Jetz, 2019). In this study, HSI model was used to quantify the habitat suitability changes of four major migratory bird guilds in DL, including Anatidae, Charadriidae, Ardeidae and Laridae. The first step of establishing HSI model is to select the habitat variables closely related to the survival of the evaluated species. According to previous studies, we selected four groups of habitat variables that affect the foraging and roost of four migratory bird guilds, including land cover type, altitude, slope and human disturbance (Wu et al., 2019b; Tang et al., 2016). 
TABLE 1 | Suitability grade of land cover types for different migratory bird guilds in DL (Tian et al., 2008a; Wu et al., 2019b).

\begin{tabular}{|c|c|c|c|c|c|c|}
\hline Birds & Phragmites & Grass & Forest & Mudflat & Shallow water & Deep water \\
\hline Anatidae & Generally & Highly & Poorly & Poorly & Moderately & Poorly \\
\hline Charadriidae & Poorly & Moderately & Poorly & Highly & Generally & Poorly \\
\hline Ardeidae & Generally & Highly & Poorly & Moderately & Highly & Poorly \\
\hline Laridae & Poorly & Generally & Poorly & Highly & Highly & Moderately \\
\hline
\end{tabular}

TABLE 2 | Suitability grade of human disturbance, altitude and slope for four migratory bird guilds in DL (Tian et al., 2008a; Wu et al., 2019b).

\begin{tabular}{|c|c|c|c|c|}
\hline- & Poorly & Generally & Moderately & Highly \\
\hline Distance to first grade road (m) & $0-600$ & $600-1,200$ & $1,200-2,400$ & $>2,400$ \\
\hline Distance to secondary road $(\mathrm{m})$ & 0-250 & $250-500$ & $500-1,000$ & $>1,000$ \\
\hline Distance to urban resident districts (m) & $0-1,200$ & $1,200-2,400$ & $2,400-4,800$ & $>4,800$ \\
\hline Distance to township settlements (m) & $0-400$ & $400-800$ & $800-1,600$ & $>1,600$ \\
\hline Altitude $(\mathrm{m})$ & $<21$ & $>35$ & $35-28$ & $28-21$ \\
\hline Gradient (degree) & $>15$ & $5-15$ & $1-5$ & $0-1$ \\
\hline
\end{tabular}

In this study, the preference and selection of migratory birds for a single habitat variable are determined based on people's understanding of migratory birds' habits (expert score) (Tian et al., 2008a; Seoane et al., 2006). For example, land cover, which directly determines the habitat type and food availability they can provide (Angradi et al., 2001). The suitability of different types of land cover for four migratory bird guilds are shown in Table 1. Similarly, we have developed a human disturbance, altitude and slope suitability grading system for migratory birds, as shown in Table 2, Human disturbance includes distance to resident district and distance to road, distance to residential area includes distance to urban resident districts and distance to township settlements, distance to road includes distance to first grade road (railway, highway, National Road, provincial road) and distance to secondary road (country road). The routes of these roads and the outline of residential areas were drawn in ArcGIS 10.7 according to Baidu map and Google map. The final score of distance to residential area is the minimum score of its two sub items, so as the distance to road. Elevation and slope data are from the digital elevation model (DEM). It is downloaded from the website: http://www.gscloud.cn/, and the resolution is also $30 \mathrm{~m}$.

The score of single variable and combined score of suitability can be divided into four grades: poorly $(0-25)$, generally (25-50), moderately (50-75) and highly (75-100). All data (including land cover type) are standardized as suitability index for HSI calculation (Zhang et al., 2017). The suitability of land cover type is standardized as the median of suitability classification interval (discontinuous value), and other indexes are standardized by piecewise linear model (continuous value) (Tian et al., 2008b).

The second step of establishing HSI model is to determine the weight of each habitat variable. In this study, the analytic hierarchy process (AHP) coupled with entropy weight method is used to determine the weight to enhance the robustness of the model (Aghajani et al., 2011; Dai et al., 2013). AHP is based on expert experience, which has certain subjectivity, but it can reduce the inconsistency of relative importance judgment through tests. The entropy weight rule provides an objective weighting method by calculating the degree of dispersion between indicators. Therefore, the final weight of each index is set as the average value of the weight determined by the two methods, as shown in Supplementary Table S2. Finally, the habitat suitability index of migratory birds in DL can be calculated by formula (1)

$$
H S I_{j}=\sum_{i=1}^{n} w_{i j} f_{i j}
$$

Among them, HSI $j$ is the HSI of the $j$ th bird $(j=1-4), n$ is the number of habitat variables, wij and $i j(i=1-\mathrm{n})$ represent the weight and suitability index of the ith habitat variables respectively.

\section{Landscape Pattern Calculation and Analysis}

The habitat suitability index calculated by the formula was reclassified to obtain the habitat suitability map of each migratory bird guild over the years. Then, the landscape index software Fragstats (version 4.2.1) was used to calculate the three indexes of classification scale (each grade), including total area (TA), largest patch index (LPI), and mean patch size (MPS).

The calculated landscape index was divided into two groups: before and after PER. The significance of the difference was analyzed by one way analysis of variance (ANOVA). Pearson correlation analysis was used to analyze the relationship between each index and the area of poplar planting. All the above analyses were analyzed by SPSS (version 25).

\section{RESULTS}

\section{Changes of Land Cover Before and After PER}

The results of land cover classification in 6 years before and after PER in DL are shown in Figure 2. It can be seen that poplar in DL 

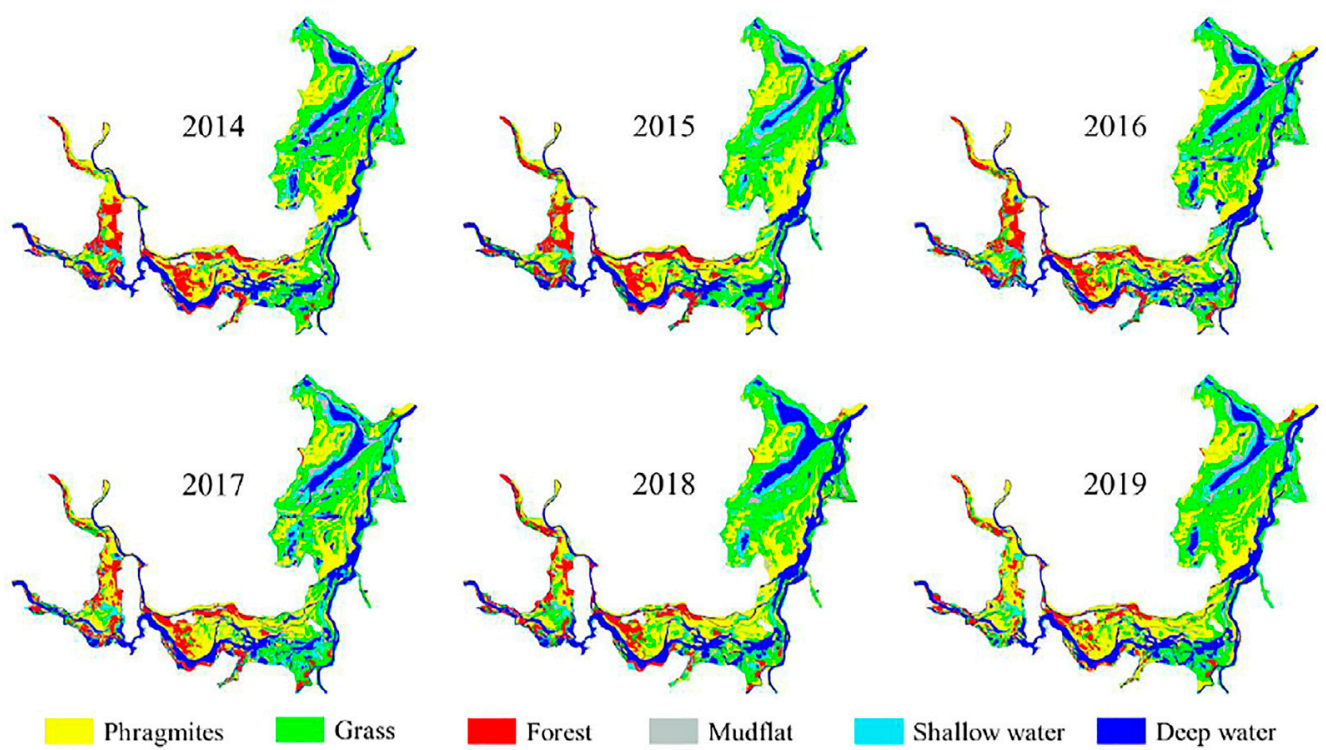

FIGURE 2 | The land cover changes of DL from 2014 to 2019 includes the 3 years before PER (2014-2016) and the 3 years after PER (2017-2019).

is mainly distributed in W-DL and S-DL, while few in E-DL and HL. The areas of various land covers are shown in Supplementary Figure S1. It showed that Phragmites, grass and deep water are the main land cover types of DL. The area of each of them is more than $500 \mathrm{~km}^{2}$, and the proportion of forest, mudflat and shallow water is small, with an area of less than $300 \mathrm{~km}^{2}$. The poplar area from 2014 to 2016 is 235.76 , 248.39 and $245.95 \mathrm{~km}^{2}$ respectively, which is close to the official data of $260 \mathrm{~km}^{2}$ (2016), showing the accuracy of our land cover interpretation work.

As can be seen from Supplementary Figure S1, the area of poplar remained stable before 2016, with a significant decrease $\left(46.12 \mathrm{~km}^{2}\right)$ in 2017, which shows the significant effect of PER in 2017. According to the report, three million poplar trees were actually cut in 2017 (Xu, 2018), with an area of about $50 \mathrm{~km}^{2}$ based on 450-750 trees per hectare, which is consistent with our analysis. Then the poplar area remained stable in 2018, and decreased significantly in 2019 (the second stage of PER). In order to explore the impacts of PER more clearly on the land cover of DL, we extracted the PER area, as shown in Supplementary Figure S2. By calculating the area, we found that 3 years after the poplar forest felled, most of the area was converted into Phragmites (79.75\%) and a small part transformed into grassland (15.16\%), but very few parts converted into other types $(5.09 \%)$.

\section{Dynamics in Habitat Suitability Over Time Anatidae}

Based on the raster calculation function of ArcGIS, the 6-year habitat suitability maps of four species of birds are generated. Figure 3 shows the dynamic changes of the habitat suitability of Anatidae over time. Due to the uneven distribution of poplar in DL, we calculated the changes of TA, LPI and MPS in the whole area and each part of DL respectively. As shown in Figure 4 for the whole study area, the TA of poor and high grade of habitat suitability are almost unchanged, but the TA of general grade decreased by $2.39 \%$, while that of the moderate grade increased by $2.20 \%$, and there was a marginal significance $(p=0.060)$. In the E-DL and HL, there was no significant change in the TA of four grades of Anatidae habitat. However, in W-DL, where there are more poplar trees and is the focus of PER, the proportion of this change is much larger than that of the whole DL, and the TA of general grade decreased by $7.07 \%$ and moderate grade increased by $5.20 \%$ in W-DL. Similarly, the TA of moderate grade in S-DL also increased significantly $(p=0.043)$. The results of Pearson correlation analysis between each index and poplar area are shown in Table $\mathbf{3}$ and Supplementary Table S3. There is a significant positive correlation between TA and MPS of general grade and poplar area in $\mathrm{W}-\mathrm{DL}$ and S-DL, while there is a significant negative correlation between TA and LPI of moderate grade and poplar area. In conclusion, PER improves the habitat suitability of Anatidae.

\section{Charadriidae}

The habitat suitability map of Charadriidae before and after PER is shown in Supplementary Figure S3. For the whole DL and each part, there is no significant change in the TA of four grade of habitat suitability. It can be seen from the Supplementary Figure S3 that most of the moderate and high suitability of habitats of Charadriidae in DL are located in the E-DL, accounting for about $70 \%$ of the whole DL, which shows the importance of E-DL as a habitat for Charadriidae. It is worth noting that the TA of high grade of Charadriidae habitat in E-DL decreased from 11.42 to $9.44 \%$, which caused a nearly significant decline in corresponded MPS ( $p=0.102)$. In terms of landscape indicators, only the decline of LPI of the high grade in W-DL and the rise of LPI of the poor grade in E-DL were significant (Figure 5), while the changes of other indexes were not obvious. In addition, in Pearson 


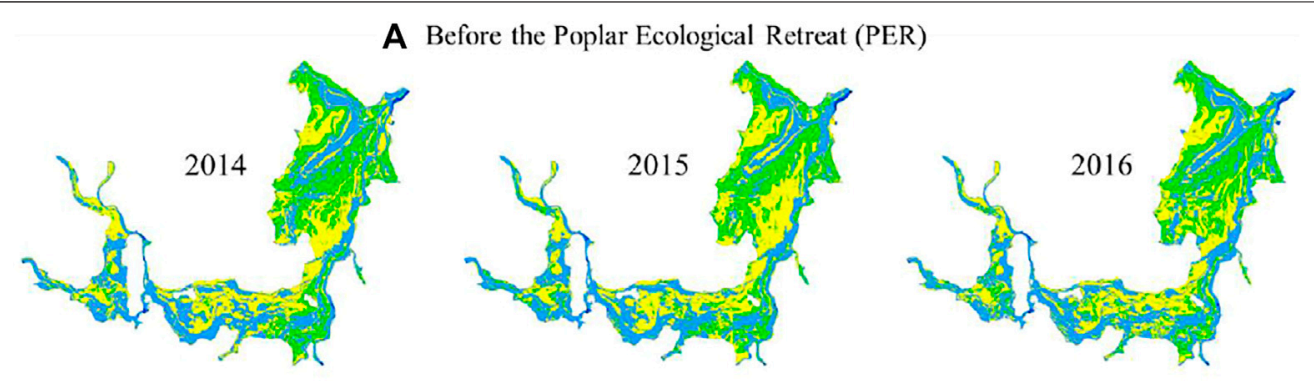

B After the Poplar Ecological Retreat (PER)
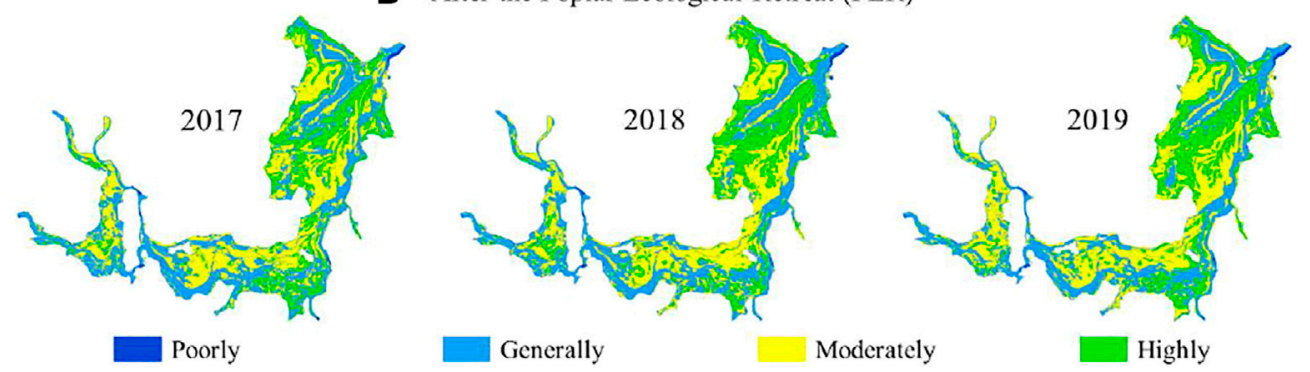

FIGURE 3 | The habitat suitability maps for Anatidae of (A) before PER (B) after PER, the habitat suitability maps for Charadriidae, Ardeidae and Laridae are showing in Supplementary Figure S2-4.

correlation analysis, only three indexes of poor grade had significant correlation with poplar area. In view of the small proportion $(<2 \%)$ of poor grade habitat of Charadriidae and the inconsistent sign of Pearson correlation coefficients, we believe that PER has no significant effect on habitat suitability of Charadriidae. Therefore, the decline of Charadriidae habitat suitability should be disturbed by other factors (see discussion).

\section{Ardeidae}

The temporal and spatial changes of habitat suitability of Ardeidae before and after PER are shown in Supplementary Figure S4. There is no obvious change in the TA of each grade of Ardeidae habitat in the whole area of DL, and the reason is like that of Anatidae. Because the unobvious changes of E-DL and HL dilute the changes of W-DL and S-DL. After PER, the general grade of habitat changed into moderate and high grade in poplarretreat area. For example, in $\mathrm{W}$-DL, the general grade habitat decreased by $6.45 \%$, and corresponded MPS has a decreasing trend $(p=0.126)$, while the moderate and high habitat increased by 5.15 and $1.25 \%$ respectively. The TA of moderate grade habitat in S-DL also increased almost significantly $(p=0.074)$. Pearson correlation analysis also showed that there was a positive correlation between TA of general grade habitats of W-DL and S-DL and poplar area, and a negative correlation between TA of moderate grade habitats and poplar area. Therefore, PER improved the habitat suitability of Ardeidae birds.

\section{Laridae}

The habitat suitability of Laridae in 3 years before and after PER is shown in Supplementary Figure S5. For TA, LPI and MPS, no matter in the whole DL or in each part, have almost no significant changes (Figures 4-6), but there are still obvious changes in individual indicators of individual grades. Firstly, the LPI of the high grade of Laridae habitat in the whole DL has decreased significantly, indicating that the largest habitat patch has been fragmented by some factor (see discussion). Secondly, the MPS of the high grade in HL increased significantly, which seems to be contradictory, because both E-DL and HL belong to the area with few poplars, so it can be determined that it is not poplars that affect these indexes, but another reason (see discussion). In Pearson correlation analysis, only MPS of high grade of E-DL had significant correlation with poplar area. In fact, poplar area of E-DL was less than $1 \%$ of the total area, so it can be concluded that PER had no significant effect on habitat suitability of Laridae.

\section{DISCUSSION}

\section{The Framework for Habitat Suitability Assessment}

In this paper, we selected the first 3 years and the last 3 years of PER as two groups of data for comparative analysis, and established the habitat suitability model to explore the impact of PER on four main migratory bird guilds in DL. We selected four groups of habitat variables, including land cover type, human disturbance (road distance and residential distance), altitude and slope, which are the four groups of habitat variables most used to evaluate bird habitat (Li et al., 2019; Tian et al., 2019; Wu et al., 2019b). Some studies also selected the normalized difference vegetation index (NDVI) as an indicator of bird food resources (Tian et al., 2008a); Tang et al., 2016; Ivajnšič et al., 2017). In this study, due to the band missing in some images and considering the strong correlation between NDVI and land cover types (Yanxia et al., 2014; Hu et al., 2020), land cover types can 
A

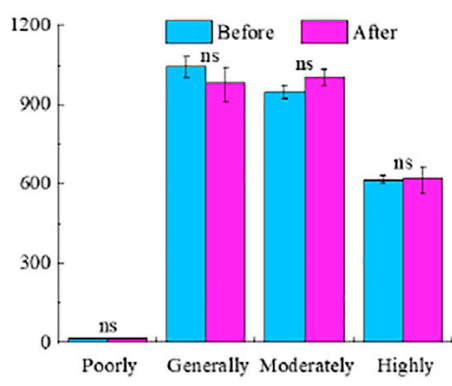

B
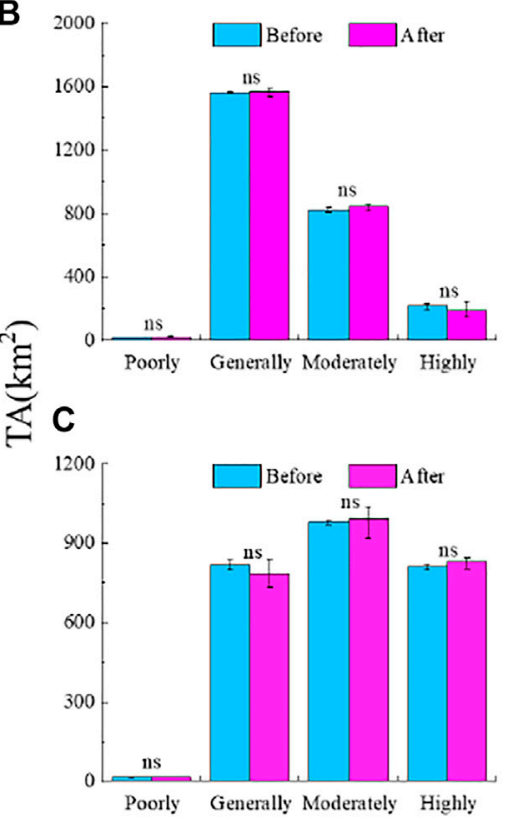

D

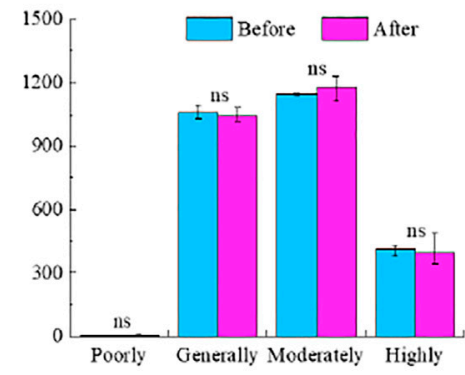

DL

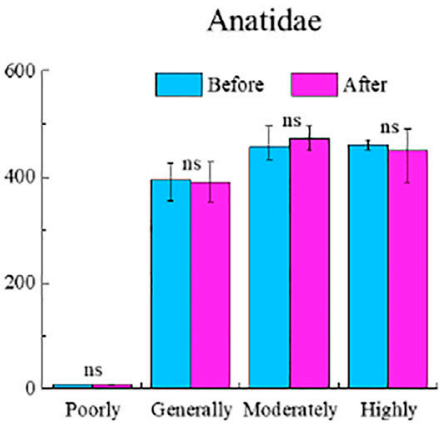

Charadriidae

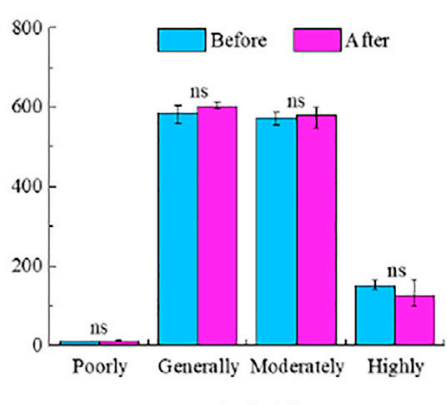

Ardeidae

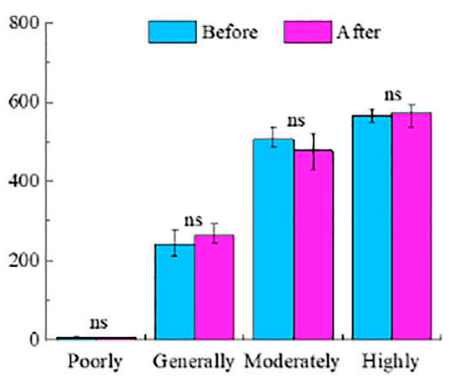

Laridae

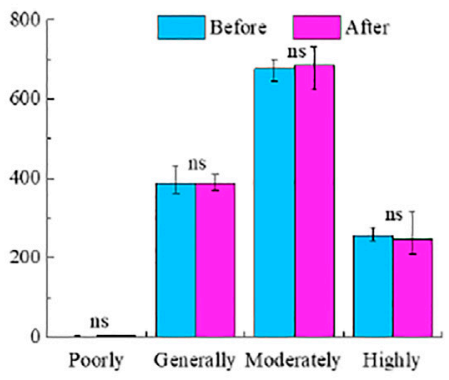

E-DL
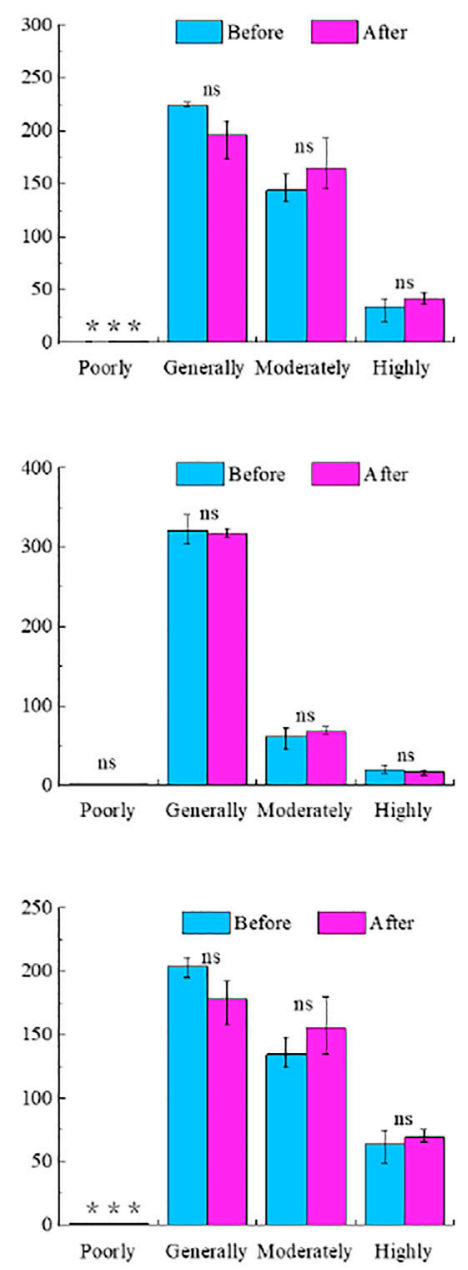

Poorly Generally Moderately Highly

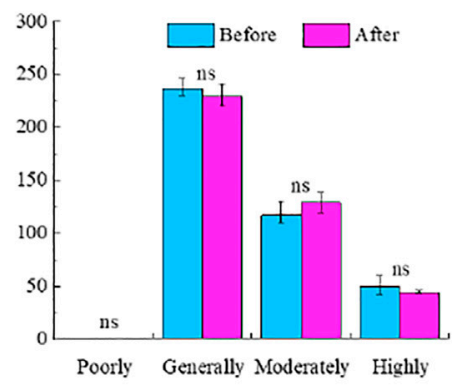

W-DL

FIGURE 4 | The TA (total area) of each grade of habitat suitability for (A) Anatidae, (B) Charadriidae, (C) Ardeidae and (D) Laridae of before PER and after PER in DL, E-DL and W-DL respectively. Error bars around the mean represent the maximum and minimum values of this group of data respectively. The information of TA in $\mathrm{HL}$ and S-DL are showing in Supplementary Figure S6.

also be used as an indirect reflection to food resources (Gan et al., 2009). Therefore, we did not choose NDVI.

We chose the HSI model because it is simple to run and does not need the presence data and absence data of the research species (Hua et al., 2012; Frantz et al., 2018; Lebeau et al., 2019). Compared with maximum entropy (MaxEnt), general additive model (GAM), general liner model (GLM), boost regression tree (BRT) and other models that need these data (Zurell et al., 2012; Brambilla et al., 2020), HSI has no training process, so it needs to determine the weight in advance, and this weight directly affects the accuracy of the model, so we carefully determine the weight, combined with the analytic hierarchy process and entropy weight 
TABLE 3 | Correlation Coefficient between Each Index of the DL (E-DL, W-DL) and their poplar area. The significance of the correlation is shown by superscript and the significant correlation coefficients are shown in bold. The information of HL and S-DL about this is showing in Supplementary Table S3.

\begin{tabular}{|c|c|c|c|c|c|c|c|c|c|c|}
\hline \multirow[t]{2}{*}{ Birds } & \multirow[t]{2}{*}{ Grade } & \multicolumn{3}{|c|}{ DL } & \multicolumn{3}{|c|}{ E-DL } & \multicolumn{3}{|c|}{ W-DL } \\
\hline & & TA & LPI & MPS & TA & LPI & MPS & TA & LPI & MPS \\
\hline \multirow[t]{4}{*}{ Anatidae } & Poorly & $0.368^{0.473}$ & $0.105^{0.843}$ & $0.394^{0.440}$ & $0.098^{0.853}$ & $0.005^{0.993}$ & $-0.151^{0.775}$ & $-0.854^{0.030}$ & $-0.682^{0.135}$ & $-0.133^{0.801}$ \\
\hline & Generally & $0.786^{0.064}$ & $-0.434^{0.390}$ & $0.776^{0.069}$ & $-0.022^{0.967}$ & $0.517^{0.293}$ & $0.124^{0.816}$ & $0.972^{0.001}$ & $0.150^{0.777}$ & $0.879^{0.021}$ \\
\hline & Moderately & $-0.861^{0.028}$ & $0.127^{0.811}$ & $-0.103^{0.846}$ & $0.183^{0.729}$ & $0.346^{0.501}$ & $0.160^{0.762}$ & $-0.867^{0.026}$ & $-0.862^{0.027}$ & $-0.206^{0.695}$ \\
\hline & Highly & $-0.377^{0.461}$ & $0.096^{0.856}$ & $0.018^{0.973}$ & $-0.128^{0.810}$ & $-0.344^{0.505}$ & $0.000^{1.000}$ & $-0.111^{0.834}$ & $0.431^{0.393}$ & $0.589^{0.219}$ \\
\hline \multirow[t]{4}{*}{ Charadriidae } & Poorly & $-0.541^{0.267}$ & $-0.931^{0.007}$ & $-0.502^{0.310}$ & $0.439^{0.383}$ & $0.926^{0.008}$ & $0.429^{0.396}$ & $-0.823^{0.044}$ & $-0.810^{0.051}$ & $-0.706^{0.117}$ \\
\hline & Generally & $-0.304^{0.558}$ & $-0.136^{0.797}$ & $0.091^{0.864}$ & $0.632^{0.178}$ & $0.290^{0.577}$ & $-0.401^{0.431}$ & $-0.099^{0.853}$ & $-0.383^{0.453}$ & $-0.261^{0.618}$ \\
\hline & Moderately & $-0.574^{0.233}$ & $0.091^{0.864}$ & $-0.607^{0.202}$ & $0.083^{0.875}$ & $0.001^{0.998}$ & $0.348^{0.499}$ & $-0.081^{0.879}$ & $-0.064^{0.904}$ & $-0.598^{0.210}$ \\
\hline & Highly & $0.469^{0.348}$ & $0.460^{0.359}$ & $0.504^{0.308}$ & $-0.501^{0.311}$ & $-0.484^{0.331}$ & $-0.664^{0.150}$ & $0.519^{0.291}$ & $0.763^{0.078}$ & $0.284^{0.585}$ \\
\hline \multirow[t]{4}{*}{ Ardeidae } & Poorly & $-0.003^{0.996}$ & $-0.044^{0.934}$ & $0.441^{0.381}$ & $0.168^{0.750}$ & $0.041^{0.939}$ & $-0.250^{0.632}$ & $-0.854^{0.030}$ & $-0.641^{0.170}$ & $-0.425^{0.401}$ \\
\hline & Generally & $0.705^{0.117}$ & $-0.428^{0.397}$ & $0.509^{0.303}$ & $0.445^{0.377}$ & $0.403^{0.429}$ & $0.414^{0.414}$ & $0.920^{0.009}$ & $0.020^{0.970}$ & $0.782^{0.066}$ \\
\hline & Moderately & $-0.416^{0.412}$ & $0.459^{0.360}$ & $0.041^{0.938}$ & $-0.395^{0.438}$ & $-0.668^{0.147}$ & $-0.093^{0.861}$ & $-0.875^{0.022}$ & $-0.642^{0.169}$ & $-0.406^{0.425}$ \\
\hline & Highly & $-0.575^{0.232}$ & $-0.381^{0.456}$ & $-0.686^{0.133}$ & $0.067^{0.900}$ & $0.359^{0.484}$ & $0.519^{0.291}$ & $-0.014^{0.979}$ & $-0.600^{0.208}$ & $-0.353^{0.493}$ \\
\hline \multirow[t]{4}{*}{ Laridae } & Poorly & $-0.534^{0.275}$ & $-0.650^{0.162}$ & $-0.770^{0.073}$ & $0.497^{0.316}$ & $0.669^{0.146}$ & $0.536^{0.272}$ & $0.275^{0.598}$ & $0.399^{0.433}$ & $0.584^{0.224}$ \\
\hline & Generally & $-0.070^{0.895}$ & $-0.062^{0.907}$ & $0.370^{0.470}$ & $0.021^{0.968}$ & $-0.098^{0.853}$ & $-0.213^{0.686}$ & $-0.056^{0.916}$ & $0.329^{0.525}$ & $0.123^{0.816}$ \\
\hline & Moderately & $-0.447^{0.375}$ & $-0.276^{0.597}$ & $-0.136^{0.798}$ & $0.184^{0.727}$ & $-0.001^{0.999}$ & $0.237^{0.651}$ & $-0.223^{0.671}$ & $0.161^{0.760}$ & $0.272^{0.603}$ \\
\hline & Highly & $0.388^{0.447}$ & $0.665^{0.149}$ & $-0.512^{0.300}$ & $-0.208^{0.693}$ & $-0.822^{0.045}$ & $0.202^{0.702}$ & $0.461^{0.357}$ & $0.440^{0.382}$ & $0.192^{0.716}$ \\
\hline
\end{tabular}

method. The importance of each habitat variable in AHP is determined according to the previous large number of studies in the same and adjacent areas (Tian et al., 2008a; Tang et al., 2016; Wu et al., 2019b), while the entropy weight is determined according to the characteristics of the habitat variables of DL. Hence, our model should be robust.

\section{Reasons of Different Responses in Different Partition}

For the four bird guilds, the response of each grade habitat in E-DL and HL is not significant, because the poplar area in these two parts is very small, it has a certain relationship with the limited water tolerance of eastern cottonwoods (Cao and Conner, 1999; Glenz et al., 2006). The elevation of E-DL and HL is lower, and the annual flooding days are longer. The elevation of W-DL and S-DL is higher, so they are more suitable for poplar growth. Before PER, the area of poplar in HL accounted for only 3.39\%, and that in E-DL was even lower, while that in W-DL and S-DL was 27.87 and $23.43 \%$ respectively. The $\mathrm{W}$-DL and the S-DL together account for only $33.91 \%$ of the total area of DL, but the area of poplar trees distributed in them accounts for $93.35 \%$ of the total area of DL, and the area of poplar retreated from them accounts for 52.44 and $39.95 \%$ of the total retreated area of DL, respectively. Therefore, the habitats of the four bird species in E-DL and HL are mainly affected by the common interannual fluctuation caused by other factors, so the changes are not obvious, while the bird habitats in W-DL and S-DL are mainly affected by the land cover type conversion caused by PER, so there are great changes.

\section{Effects of PER on Habitat Suitability of Different Birds}

Although the land cover types of W-DL and S-DL have changed greatly after PER, only the habitat suitability of Anatidae and
Ardeidae has been improved in the end. This is due to the different preferences of these birds for land cover types (Tian et al., 2008a). After poplar trees are cut down, the roots are easy to rot after being soaked in water, and they can return to the previous wetland state as soon as one or 2 years (Liu et al., 2020). The result of the image interpretation shows that most of the poplar felled areas are converted into Phragmites areas, and a small part into grassland, which can improve the habitat of Anatidae and Ardeidae, but for Charadriidae and Laridae, they prefer mudflat and shallow water habitats to Phragmites, and the mudflat and shallow water areas are more strongly affected by hydrological factors (Hu et al., 2015).

\section{Influence of Other Factors}

In this study, we focus on the effect of PER on the habitat suitability of four migratory bird guilds in DL. However, it is undeniable that our study is also affected by other factors, the most important of which is hydrology (Wang et al., 2019). As mentioned above, the habitat suitability of Charadriidae and Laridae has declined slightly. Through analysis, we find that this is caused by different water levels, and there are two main reasons: firstly, the actual hydrological situation of DL is different every year. Secondly, due to the limitation of the availability of the image, there is a certain interval in the time of our selection. According to the interpretation, the area of deep water area increased significantly, the shallow water area changed little, but the mudflat decreased significantly. This is obviously caused by different water levels corresponding to images in different years (Wu et al., 2020). For this cause, the habitat suitability of Charadriidae and Laridae decreased. The reason for the significant decrease of LPI of the high grade of Laridae habitat in the E-DL is that the habitat is separated by the deep water area. As for the increase of MPS of the high grade in HL, we speculate that the rising of water level may make the water level of HL more suitable for Laridae, because HL is located in the upper reaches of E-DL with higher elevation (Yao et al., 2019). 
A

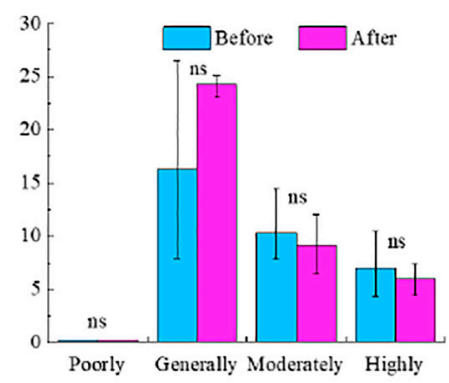

B

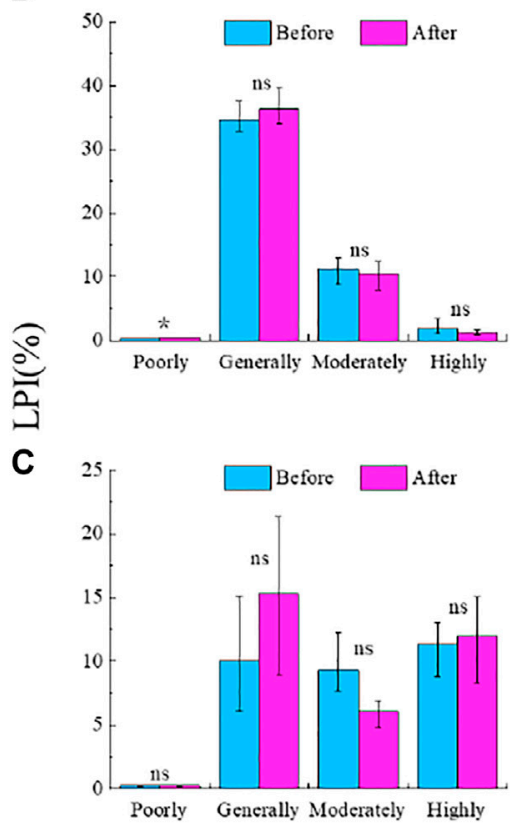

D

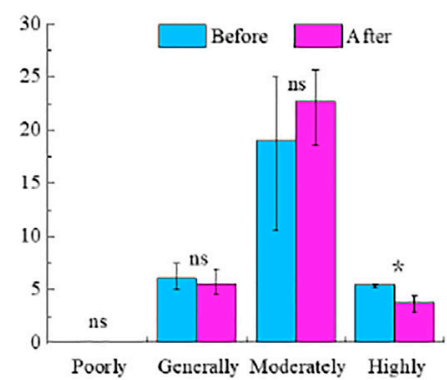

DL
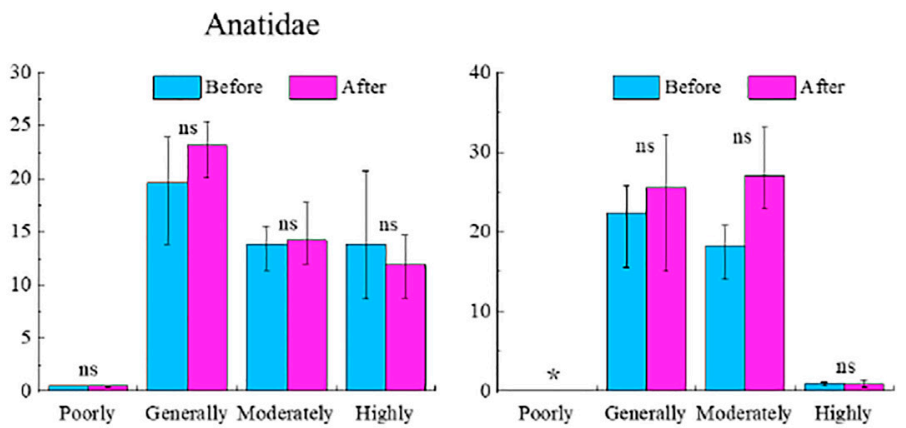

Charadriidae
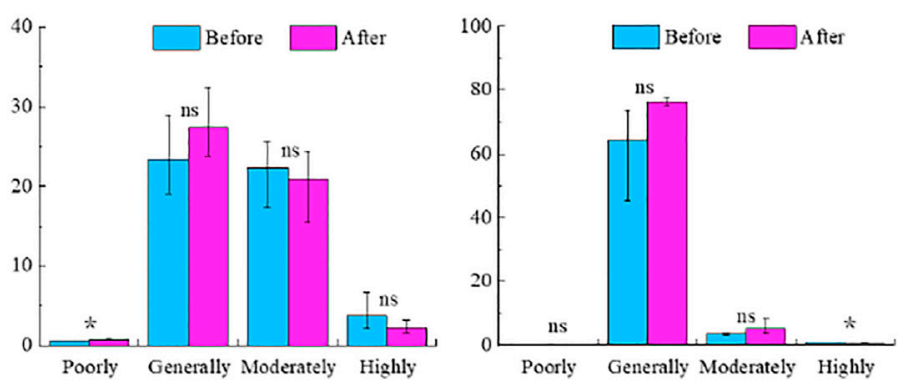

Ardeidae
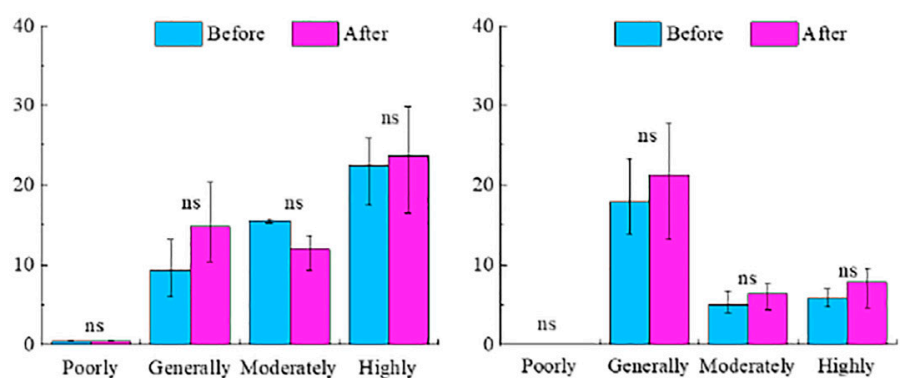

Laridae

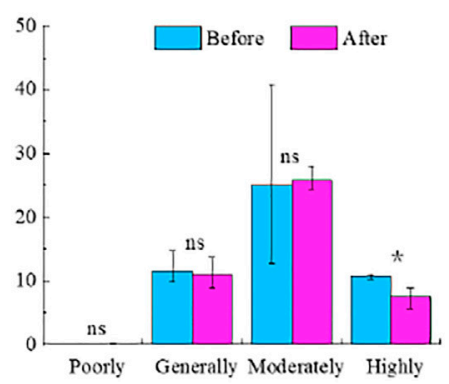

E-DL

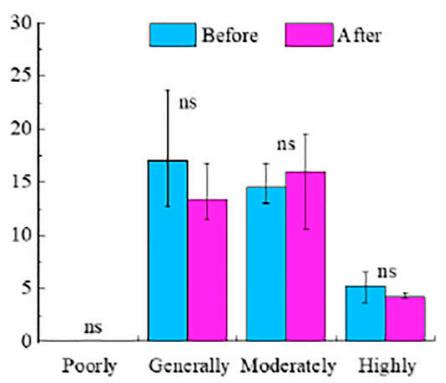

W-DL

FIGURE 5 | The LPI (Largest patch index) of each grade of habitat suitability for (A) Anatidae, (B) Charadriidae, (C) Ardeidae and (D) Laridae of before PER and after PER in DL, E-DL and W-DL respectively. Error bars around the mean represent the maximum and minimum values of this group of data respectively. The information of $\mathrm{LPI}$ in $\mathrm{HL}$ and $\mathrm{S}-\mathrm{DL}$ are showing in Supplementary Figure $\mathbf{S 7}$.

\section{CONCLUSION}

Climate change and human activities are the two most important factors affecting biodiversity, and land use change is the most important part of human activities. This study is a typical case of the impact of land use change on the habitat suitability of wetland birds. The results of this study show that: 1) the poplar area of DL is significantly correlated with the three indicators of habitat suitability of Anatidae and Ardeidae; 2) PER makes the general grade habitat of some Anatidae and 
A

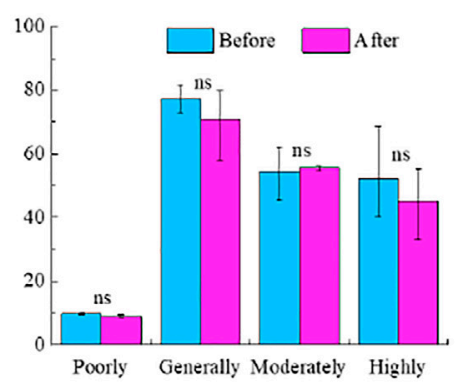

B

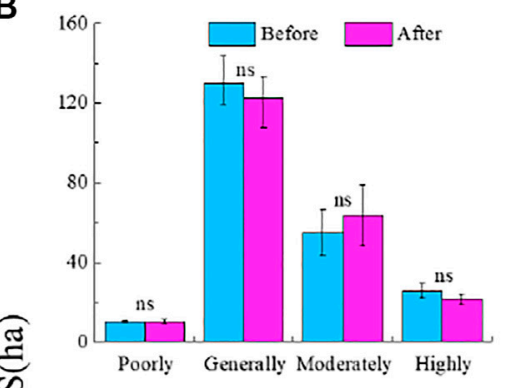

C

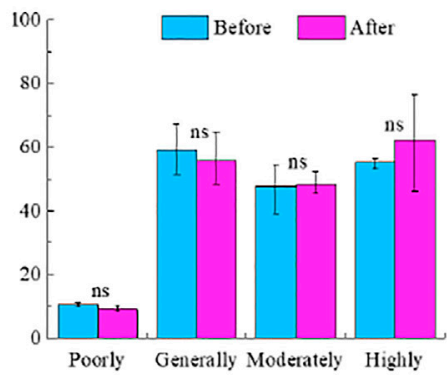

D

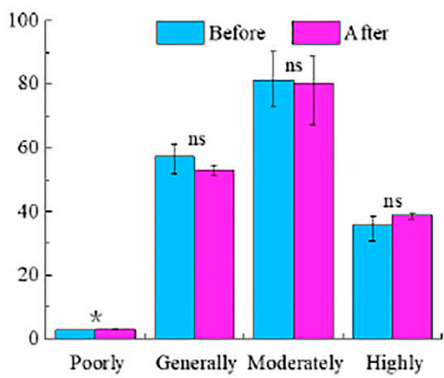

DL

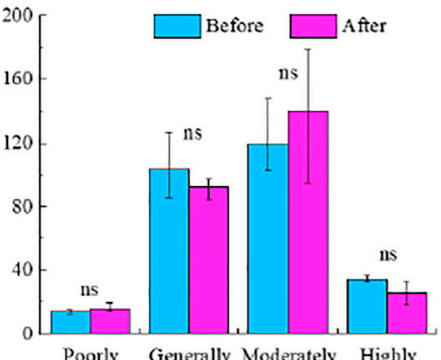

Ardeidae
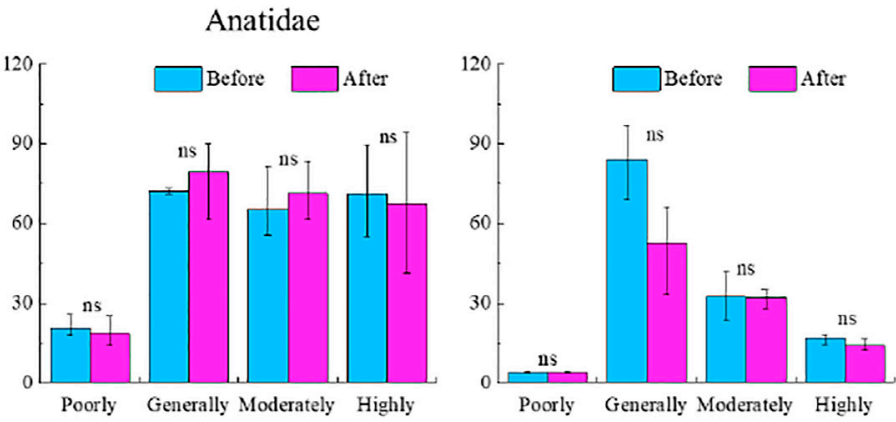

Charadriidae

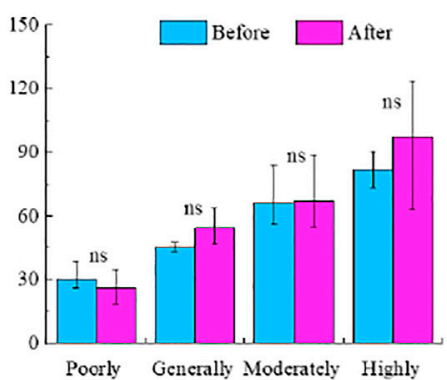

Laridae

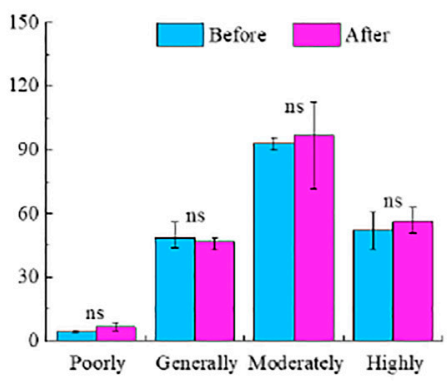

E-DL
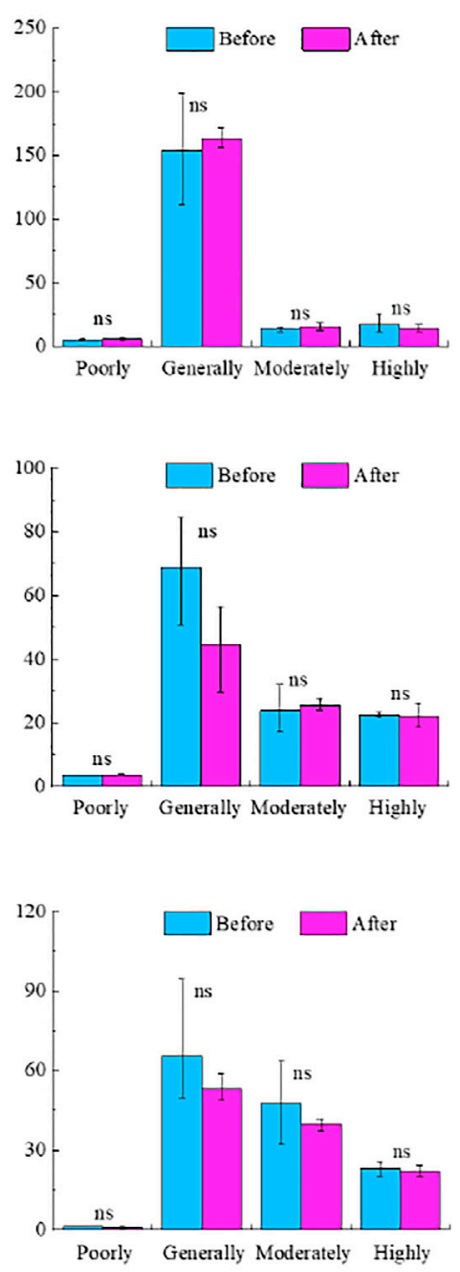

W-DL

FIGURE 6 | The MPS (Mean patch size) of each grade of habitat suitability for (A) Anatidae, (B) Charadriidae, (C) Ardeidae and (D) Laridae of before PER and after $P E R$ in DL, E-DL and W-DL respectively. Error bars around the mean represent the maximum and minimum values of this group of data respectively. The information of MPS in HL and S-DL are showing in Supplementary Figure S8.

Ardeidae change to moderate and the high grade, which improves the habitat suitability of Anatidae and Ardeidae; 3) PER had no significant effect on the habitat suitability of Charadriidae and Laridae, and the change of habitat suitability of Charadriidae and Laridae was mainly affected by hydrology. PER is still being implemented, and future studies need to continue to pay attention to the impact of PER on habitat suitability of migratory birds in Dongting Lake. Moreover, these studies could consider adding bird population and distribution data to test the accuracy of the model or establish a model which can automatically determine weight through training by using distribution data. 


\section{DATA AVAILABILITY STATEMENT}

The original contributions presented in the study are included in the article/Supplementary Material, further inquiries can be directed to the corresponding author.

\section{AUTHOR CONTRIBUTIONS}

$\mathrm{XQ}$ and $\mathrm{CD}$ performed the studies and drafted the manuscript; HW designed the study, YX contributed to data analysis; GY and JW participated in the study design; JD, LW, ZZ, YZ and JL contributed to revision and improvement for the manuscript.

\section{REFERENCES}

Aghajani Bazzazi, A., Osanloo, M., and Karimi, B. (2011). Deriving Preference Order of Open Pit Mines Equipment through MADM Methods: Application of Modified VIKOR Method. Expert Syst. Appl. 38 (3), 2550-2556. doi:10.1016/ j.eswa.2010.08.043

Angradi, T. R., Hagan, S. M., and Able, K. W. (2001). Vegetation Type and the Intertidal Macroinvertebrate Fauna of a Brackish Marsh: Phragmites vs. Spartina. Wetlands 21 (1), 75-92. doi:10.1672/0277-5212(2001)021[0075: vtatim]2.0.co;2

Bai, M.-L., Chih, W.-C., Lai, Y.-C., Lee, P.-F., and Lien, Y.-Y. (2018). Aquaculture Ponds as Important High-Tide Habitats for Waterbirds along the West Coast of Taiwan. Ornithological Sci. 17 (1), 55-67. doi:10.2326/osj.17.55

Brambilla, M., Scridel, D., Bazzi, G., Ilahiane, L., Iemma, A., Pedrini, P., et al. (2020). Species Interactions and Climate Change: How the Disruption of Species Co-occurrence Will Impact on an Avian forest Guild. Glob. Change Biol. 26 (3), 1212-1224. doi:10.1111/gcb.14953

Cao, F. L., and Conner, W. H. (1999). Selection of Flood-Tolerant Populus Deltoides Clones for Reforestation Projects in China. For. Ecol. Manag. 117 (1), 211-220. doi:10.1016/S0378-1127(98)00465-4

Ceccarelli, T., Smiraglia, D., Bajocco, S., Rinaldo, S., De Angelis, A., Salvati, L., et al. (2013). Land Cover Data from Landsat Single-Date Imagery: an Approach Integrating Pixel-Based and Object-Based Classifiers. Eur. J. Remote Sensing 46 (1), 699-717. doi:10.5721/EuJRS20134641

Dai, X., Ma, J., Zhang, H., and Xu, W. (2013). Evaluation of Ecosystem Health for the Coastal Wetlands at the Yangtze Estuary, Shanghai. Wetlands Ecol. Manage. 21 (6), 433-445. doi:10.1007/s11273-013-9316-4

Ding, X., and Li, X. (2011). Monitoring of the Water-Area Variations of Lake Dongting in China with ENVISAT ASAR Images. Int. J. Appl. Earth Observation Geoinformation 13 (6), 894-901. doi:10.1016/ j.jag.2011.06.009

Drăguț, L., Tiede, D., and Levick, S. R. (2010). ESP: a Tool to Estimate Scale Parameter for Multiresolution Image Segmentation of Remotely Sensed Data. Int. J. Geogr. Inf. Sci. 24 (6), 859-871. doi:10.1080/13658810903174803

Fang, J., Wang, Z., Zhao, S., Li, Y., Tang, Z., Yu, D., et al. (2006). Biodiversity Changes in the Lakes of the Central Yangtze. Front. Ecol. Environ. 4 (7), 369-377. doi:10.1890/1540-9295(2006)004[0369:bcitlo]2.0.co;2

Frantz, M. W., Wood, P. B., Sheehan, J., and George, G. (2018). Demographic Response of Louisiana Waterthrush, a Stream Obligate Songbird of Conservation Concern, to Shale Gas Development. The Condor 120 (2), 265-282. doi:10.1650/CONDOR-17-130.1

Gan, X., Cai, Y., Choi, C., Ma, Z., Chen, J., and Li, B. (2009). Potential Impacts of Invasive Spartina Alterniflora on spring Bird Communities at Chongming Dongtan, a Chinese Wetland of International Importance. Estuarine, Coastal Shelf Sci. 83 (2), 211-218. doi:10.1016/j.ecss.2009.03.026

Glenz, C., Schlaepfer, R., Iorgulescu, I., and Kienast, F. (2006). Flooding Tolerance of Central European Tree and Shrub Species. For. Ecol. Manage. 235 (1), 1-13. doi:10.1016/j.foreco.2006.05.065

\section{FUNDING}

This research was financially supported by the National Natural Science Foundation of China (51809011), the Scientific Research Foundation of Hunan Provincial Education Department (21A0188, 20B005) and the Natural Science Foundation of Hunan Province (2021JJ40601).

\section{SUPPLEMENTARY MATERIAL}

The Supplementary Material for this article can be found online at: https:/www.frontiersin.org/articles/10.3389/fenvs.2021.793005/ full\#supplementary-material

Guan, L., Lei, J., Zuo, A., Zhang, H., Lei, G., and Wen, L. (2016). Optimizing the Timing of Water Level Recession for Conservation of Wintering Geese in Dongting Lake, China. Ecol. Eng. 88, 90-98. doi:10.1016/j.ecoleng.2015.12.009

$\mathrm{Hu}, \mathrm{J}$., and Liu, Y. (2014). Unveiling the Conservation Biogeography of a DataDeficient Endangered Bird Species under Climate Change. PLoS One 9, e84529. doi:10.1371/journal.pone.0084529

Hu, W., Li, G., Gao, Z., Jia, G., Wang, Z., and Li, Y. (2020). Assessment of the Impact of the Poplar Ecological Retreat Project on Water Conservation in the Dongting Lake Wetland Region Using the InVEST Model. Sci. Total Environ. 733, 139423. doi:10.1016/j.scitotenv.2020.139423

Hu, Y.-X., Huang, J.-l., Du, Y., Han, P.-p., Wang, J.-l., and Huang, W. (2015). Monitoring Wetland Vegetation Pattern Response to Water-Level Change Resulting from the Three Gorges Project in the Two Largest Freshwater Lakes of China. Ecol. Eng. 74, 274-285. doi:10.1016/j.ecoleng.2014.10.002

Hua, Y., Cui, B., and He, W. (2012). Changes in Water Birds Habitat Suitability Following Wetland Restoration in the Yellow River Delta, China. Clean. Soil Air Water 40 (10SI), 1076-1084. doi:10.1002/clen.201200064

Ivajnšič, D., Lipej, L., Škornik, I., and Kaligarič, M. (2017). The Sea Level Rise Impact on Four Seashore Breeding Birds: the Key Study of Sečovlje Salina Nature Park. Climatic Change 140 (3-4), 549-562. doi:10.1007/s10584-0161854-3

Jia, M., Wang, Z., Li, L., Song, K., Ren, C., Liu, B., et al. (2013). Mapping China's Mangroves Based on an Object-Oriented Classification of Landsat Imagery. Wetlands 34, 277-283. doi:10.1007/s13157-013-0449-2

Jing, L., Lyu, C., Zhou, Y., Zuo, A. J., and Lei, G. C. (2016). Spatio-temporal Characteristics of the Expansion of poplar Plantation in West Dongting Lake Wetland, China. Ying Yong Sheng Tai Xue Bao 27 (7), 2039-2047. doi:10.13287/ j.1001-9332.201607.025

Lebeau, C. W., Smith, K. T., Holloran, M. J., Beck, J. L., Kauffman, M. E., and Johnson, G. D. (2019). Greater Sage-grouse Habitat Function Relative to 230kV Transmission Lines. Jour. Wild. Mgmt. 83 (8), 1773-1786. doi:10.1002/ jwmg. 21749

Li, F., Huang, J., Zeng, G., Yuan, X., Li, X., Liang, J., et al. (2013). Spatial Risk Assessment and Sources Identification of Heavy Metals in Surface Sediments from the Dongting Lake, Middle China. J. Geochemical Exploration 132, 75-83. doi:10.1016/j.gexplo.2013.05.007

Li, N., Wang, Z., Xia, L., Yan, F., Xu, L.-q., Qiao, Y.-j., et al. (2019). Effects of LongTerm Coastal Reclamation on Suitable Habitat and Wintering Population Size of the Endangered Red-Crowned Crane, Grus japonensis. Hydrobiologia 827 (1), 21-29. doi:10.1007/s10750-017-3341-x

Li, Q., Yu, M., Lu, G., Cai, T., Bai, X., and Xia, Z. (2011). Impacts of the Gezhouba and Three Gorges Reservoirs on the Sediment Regime in the Yangtze River, China. J. Hydrol. 403 (3), 224-233. doi:10.1016/ j.jhydrol.2011.03.043

Li, Y., Chen, X., Xie, Y., Li, X., Li, F., and Hou, Z. (2014a). Effects of Young poplar Plantations on Understory Plant Diversity in the Dongting Lake Wetlands, China. Sci. Rep. 4, 6339. doi:10.1038/srep06339

Li, Y., Qin, H., Xie, Y., Wang, W., Chen, X., and Zhang, C. (2014b). Physiological Mechanism for the Reduction in Soil Water in poplar (Populus Deltoides) 
Plantations in Dongting Lake Wetlands. Wetlands Ecol. Manage. 22 (1), 25-33. doi:10.1007/s11273-013-9319-1

Liu, J. Y., Niu, Y. D., Guo, K. J., Luo, X. W., Yang, R., and Jiang, L. J. (2020). Characteristics of Soil Seed Bank and Their Correlations with Soil Factors in the Early Restoration Period of Populus Deltoides Cutting Slash in Lake South Dongting, China. Ying Yong Sheng Tai Xue Bao 31 (12), 4042-4050. doi:10.13287/j.1001-9332.202012.005

Ma, T., Li, X., Bai, J., and Cui, B. (2019). Habitat Modification in Relation to Coastal Reclamation and its Impacts on Waterbirds along China's Coast. Glob. Ecol. Conservation 17, e00585. doi:10.1016/j.gecco.2019.e00585

Meng, W., He, M., Hu, B., Mo, X., Li, H., Liu, B., et al. (2017). Status of Wetlands in China: A Review of Extent, Degradation, Issues and Recommendations for Improvement. Ocean Coastal Manage. 146 (sep), 50-59. doi:10.1016/ j.ocecoaman.2017.06.003

Miranda, L. S., Imperatriz-Fonseca, V. L., and Giannini, T. C. (2019). Climate Change Impact on Ecosystem Functions provided by Birds in southeastern Amazonia. PLoS One 14, e0215229. doi:10.1371/journal.pone.0215229

Powers, R. P., and Jetz, W. (2019). Global Habitat Loss and Extinction Risk of Terrestrial Vertebrates under Future Land-Use-Change Scenarios. Nat. Clim. Chang. 9 (4), 323-329. doi:10.1038/s41558-019-0406-z

Ren, B., Xie, Y., and Li, Y. (2020). Understory Floristic Diversity in Poplar Plantations in the Dongting Lake Wetlands, China. Wetlands 40 (5), 1549-1560. doi:10.1007/s13157-019-01255-7

Scholtz, R., Polo, J., Fuhlendorf, S., and Duckworth, G. (2017). Land Cover Dynamics Influence Distribution of Breeding Birds in the Great Plains, USA. Biol. Conservation 209, 323-331. doi:10.1016/j.biocon.2017.02.028

Seoane, J., Justribó, J. H., García, F., Retamar, J., Rabadán, C., and Atienza, J. C. (2006). Habitat-suitability Modelling to Assess the Effects of Land-Use Changes on Dupont's Lark Chersophilus Duponti: A Case Study in the Layna Important Bird Area. Biol. Conservation 128 (2), 241-252. doi:10.1016/j.biocon.2005.09.032

Tang, X., Li, H., Xu, X., Yang, G., Liu, G., Li, X., et al. (2016). Changing Land Use and its Impact on the Habitat Suitability for Wintering Anseriformes in China's Poyang Lake Region. Sci. Total Environ. 557-558, 296-306. doi:10.1016/ j.scitotenv.2016.03.108

Tian, B., Zhou, Y., Zhang, L., Ma, Z., Yang, B., and Tang, C. (2008a). A GIS and Remote Sensing-Based Analysis of Migratory Bird Habitat Suitability for Chongm Ing Dongtan Nature Reserve, Shanghai. Acta Ecologica Sinica 28 (7), 3049-3059.

Tian, B., Zhou, Y., Zhang, L., and Yuan, L. (2008b). Analyzing the Habitat Suitability for Migratory Birds at the Chongming Dongtan Nature Reserve in Shanghai, China. Estuarine, Coastal Shelf Sci. 80 (2), 296-302. doi:10.1016/ j.ecss.2008.08.014

Tian, Y., Wang, Z., Mao, D., Li, L., Liu, M., Jia, M., et al. (2019). Remote Observation in Habitat Suitability Changes for Waterbirds in the West Songnen Plain, China. Sustainability 11 (15526), 1552. doi:10.3390/su11061552

USGS (2019). Landsat Collection 1 Level 1 Product Definition. Available at: https:// prd-wret.s3.us-west-2.amazonaws.com/assets/palladium/production/atoms/files/ LSDS-1656_\%20Landsat_Collection1_L1_Product_Definition-v2.pdf.

Vieira, M. A., Formaggio, A. R., Rennó, C. D., Atzberger, C., Aguiar, D. A., and Mello, M. P. (2012). Object Based Image Analysis and Data Mining Applied to a Remotely Sensed Landsat Time-Series to Map Sugarcane over Large Areas. Remote Sensing Environ. 123, 553-562. doi:10.1016/j.rse.2012.04.011

Wang, M., Gu, Q., Liu, G., Shen, J., and Tang, X. (2019). Hydrological Condition Constrains Vegetation Dynamics for Wintering Waterfowl in China's East Dongting Lake Wetland. Sustainability 11, 4936. doi:10.3390/su11184936

Wu, H., Chen, J., Xu, J., Zeng, G., Sang, L., Liu, Q., et al. (2019a). Effects of Dam Construction on Biodiversity: A Review. J. Clean. Prod. 221, 480-489. doi:10.1016/j.jclepro.2019.03.001

Wu, H., Hu, X., Sun, S., Dai, J., Ye, S., Du, C., et al. (2020). Effect of Increasing of Water Level during the Middle of Dry Season on Landscape Pattern of the Two
Largest Freshwater Lakes of China. Ecol. Indicators 113, 106283. doi:10.1016/ j.ecolind.2020.106283

Wu, H., Chen, J., Zeng, G., Xu, J., Sang, L., et al. (2019b). Effects of Early Dry Season on Habitat Suitability for Migratory Birds in China's Two Largest Freshwater Lake Wetlands after the Impoundment of Three Gorges Dam. J. Environ. Inform 36, 82-92. doi:10.3808/jei.201900411

Wu, H., Zeng, G., Liang, J., Chen, J., Xu, J., Dai, J., et al. (2017). Responses of Landscape Pattern of China's Two Largest Freshwater Lakes to Early Dry Season after the Impoundment of Three-Gorges Dam. Int. J. Appl. Earth Observation Geoinformation 56, 36-43. doi:10.1016/j.jag.2016.11.006

Wu, J. X., Wilsey, C. B., Taylor, L., and Schuurman, G. W. (2018). Projected Avifaunal Responses to Climate Change across the U.S. National Park System. PLoS One 13, e0190557. doi:10.1371/journal.pone.0190557

Xie, Y.-h., Yue, T., Xin-sheng, C., Feng, L., and Zheng-miao, D. (2015). The Impact of Three Gorges Dam on the Downstream Eco-Hydrological Environment and Vegetation Distribution of East Dongting Lake. Ecohydrol. 8 (4), 738-746. doi:10.1002/eco.1543

Xu, Q. (2018). Cutting Trees in Dongting" Should Not Be Repeated. Beijing daily. 2018-01-05. doi:10.28033/n.cnki.nbjrb.2018.000375

Yang, G., Xie, Y. H., Chen, X. S., Hou, Z. Y., and Li, F. (2009). Soil Enzyme Activities under Different Restoration Modes after Returning farmland to lake in Dongting Lake Area. Ying Yong Sheng Tai Xue Bao 20 (9), 2187-2192.

Yanxia, H., Jinliang, H., Yun, D., Pengpeng, H., Jiuling, W., and Wei, H. (2014). Research on Methods for Extracting Change Information of the Fast-Growing poplar in Dongting Lake. Acta Eco Sin 34 (24), 7243-7250. doi:10.5846/ stxb201310162491

Yao, S., Li, X., Liu, C., Yuan, D., Zhu, L., Ma, X., et al. (2019). Quantitative Assessment of Impact of the Proposed Poyang Lake Hydraulic Project (China) on the Habitat Suitability of Migratory Birds. Water 11, 1639. doi:10.3390/ w11081639

Yuan, Y., Zeng, G., Liang, J., Li, X., Li, Z., Zhang, C., et al. (2014). Effects of Landscape Structure, Habitat and Human Disturbance on Birds: A Case Study in East Dongting Lake Wetland. Ecol. Eng. 67, 67-75. doi:10.1016/ j.ecoleng.2014.03.012

Zhang, Y., Wang, Z., Ren, C., Yu, H., Dong, Z., Lu, C., et al. (2017). Changes in Habitat Suitability for Waterbirds of the Momoge Nature Reserve of China during 1990-2014. J. Environ. Eng. Landsc. 25 (4), 367-378. doi:10.3846/ 16486897.2017.1316982

Zurell, D., Grimm, V., Rossmanith, E., Zbinden, N., Zimmermann, N. E., and Schröder, B. (2012). Uncertainty in Predictions of Range Dynamics: Black Grouse Climbing the Swiss Alps. Ecography 35 (7), 590-603. doi:10.1111/ j.1600-0587.2011.07200.x

Conflict of Interest: The authors declare that the research was conducted in the absence of any commercial or financial relationships that could be construed as a potential conflict of interest.

Publisher's Note: All claims expressed in this article are solely those of the authors and do not necessarily represent those of their affiliated organizations, or those of the publisher, the editors and the reviewers. Any product that may be evaluated in this article, or claim that may be made by its manufacturer, is not guaranteed or endorsed by the publisher.

Copyright (c) $2022 \mathrm{Qu}, \mathrm{Du}, \mathrm{Wu}$, Xiong, Yu, Wang, Dai, Wu, Zhang, Zhu and Liu. This is an open-access article distributed under the terms of the Creative Commons Attribution License (CC BY). The use, distribution or reproduction in other forums is permitted, provided the original author(s) and the copyright owner(s) are credited and that the original publication in this journal is cited, in accordance with accepted academic practice. No use, distribution or reproduction is permitted which does not comply with these terms. 